\title{
La estela de Paser en el Museo Egipcio de El Cairo (CG 34038)
}

\section{Belén Castro*}

Resumen

Este artículo presenta una estela del Museo Egipcio de El Cairo (CG 34038). Se trata de un monumento de caliza proveniente del yacimiento de Abidos y de formato conocido como round-topped, es decir, con la parte superior redondeada. Presenta un buen estado de preservación general, aunque la sección superior ha sufrido daños sobre la inscripción. La estela — datada en la dinastía XVIII del Reino Nuevo- representa a tres personajes en torno a una mesa de ofrendas, junto con textos de fórmula de ofrendas. Se incluye la transcripción, transliteración y traducción de la inscripción, así como comentarios sobre su contenido.

\section{The Paser Stela in the Egyptian Museum of Cairo (CG 34038)}

\begin{abstract}
This paper presents a stela from the Cairo Egyptian Museum (CG 34038). It is a limestone monument from Abydos and belongs to the round-topped style, which means that its upper part is rounded. The monument shows a good general preservation state, although the hieroglyphic inscription is damaged in its upper section. The stela -dated to the Eighteen Dynasty (Dynasty XVIII) of the New Kingdom- depicts three individuals next to an offering table, along with offering formula texts. This paper includes the transcription, transliteration, and translation of the text, together with comments about its content.
\end{abstract}

Recibido: 27 de abril de 2019

Aceptado:

9 de diciembre de 2019

\section{Palabras clave}

Estela

Reino Nuevo

Abidos

Museo Egipcio de El Cairo

\section{Keywords}

\section{Stela}

New Kingdom

Abydos

Cairo Egyptian Museum

* Centro de Estudios de Sociedades Precapitalistas. Instituto de Investigaciones en Humanidades y Ciencias Sociales, 
1. En el catálogo de documentos que sistematiza Simpson (1974) se aprecia esta decoración particular en numerosos casos. El motivo puede incluir también a dos Anubis sobre capillas ( enfrentados.

\section{Introducción}

La estela CG 34038, conservada y exhibida actualmente en el Museo de El Cairo, perteneció a un individuo llamado Paser. Fue encontrada en la necrópolis norte en Abidos en torno al año 1861 por Auguste Mariette. De acuerdo con sus observaciones, su decoración - destacada por su "elegancia" - se asemeja a otra serie de monumentos provenientes del mismo yacimiento a los que fecha en el reinado de Tutmosis III (Mariette, 1880). El amplio registro del programa constructivo y decorativo de este faraón permite al autor establecer una referencia a fin de confirmar esta datación. La estela de Paser recibe en el Catalogue Général des Monuments d’Abydos el número 1052.

La estela había sido registrada en el Journal d'Entrée del Museo de El Cairo con el número de orden 15114, que devendrá en ese acto en la numeración final del Museo: 34038. Allí se ratifica 1861 como año de descubrimiento del monumento y Abidos como sitio de procedencia.

En el año 1909 Pierre Lacau publica el Catalogue Général des Antiquités Égyptiennes du Musée du Caire. Nos 34001-34064. Allí se incluye bajo la numeración 34038 a la estela de Paser. El autor ofrece una descripción y transcripción de la estela, así como una foto sumaria en blanco y negro. Destaca ya como diagnóstico de su conservación el hecho de que la parte superior está muy roída y los colores han desaparecido "casi por completo" (Lacau, 1909, pp. 72-73).

La estela se conserva y exhibe actualmente en el Museo de El Cairo (Figura 1). Catalogada como estela funeraria privada, mide 56 centímetros de ancho por 82 centímetros de alto. La parte superior se encuentra, efectivamente, severamente dañada. La decoración sobre la luneta redondeada incluye dos ojos wedjat que se observan borroneados, especialmente el de la derecha. Es posible que el motivo incluyera un anillo shen entremedio de los ojos, como parte del motivo iconográfico ampliamente reconocido a partir de las estelas del Reino Medio ${ }^{1}$, pero no es factible distinguirlo con claridad. Los signos jeroglíficos que subyacen a los ojos han perdido igualmente la profundidad de su bajo relieve, por lo que la lectura de la inscripción se dificulta. El nombre del propietario de la estela, efectivamente, sólo puede ser confirmado en la inscripción de ofrenda que se registra en la mitad inferior del monumento, aun cuando ya se incluía en la inscripción superior. Tal como ya lo afirmaba Lacau (1909), los vestigios de color son prácticamente nulos.

La composición completa de la estela consta de la decoración en la luneta superior previamente mencionada, un registro medio que combina imagen y texto y una inscripción a partir de la mitad que se extiende por siete líneas. Esta última serie de signos se presenta clara y completa.

La imagen del centro de la estela condensa una escena de presentación de ofrendas. Un personaje, sobre la izquierda, se encuentra de pie haciendo una libación sobre la mesa de ofrendas. Porta en su mano derecha una jarra $\bar{I}$, lleva su cabeza rapada y un faldellín drapeado a la rodilla. Sobre él, los signos jeroglíficos ofrecen información sobre

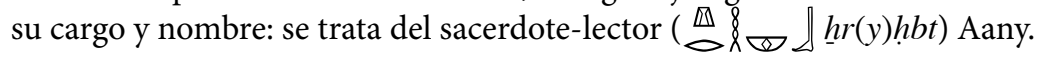

En el centro, la nutrida mesa de ofrendas incluye numerosos productos, entre los que se destacan un ave, cebollas, melón, uvas y diferentes tipos de panes. Por debajo, a cada lado del centro de la mesa, se apoyan sobre el suelo dos jarrones que se encuentran envueltos con un loto.

Hacia la derecha, un hombre y mujer recepcionan la ofrenda. Están sentados, mirando hacia la izquierda. El sillón sobre el que se sientan tiene patas de león y pareciera haber una base debajo del mismo. El hombre lleva su cabeza afeitada, un collar al cuello y 


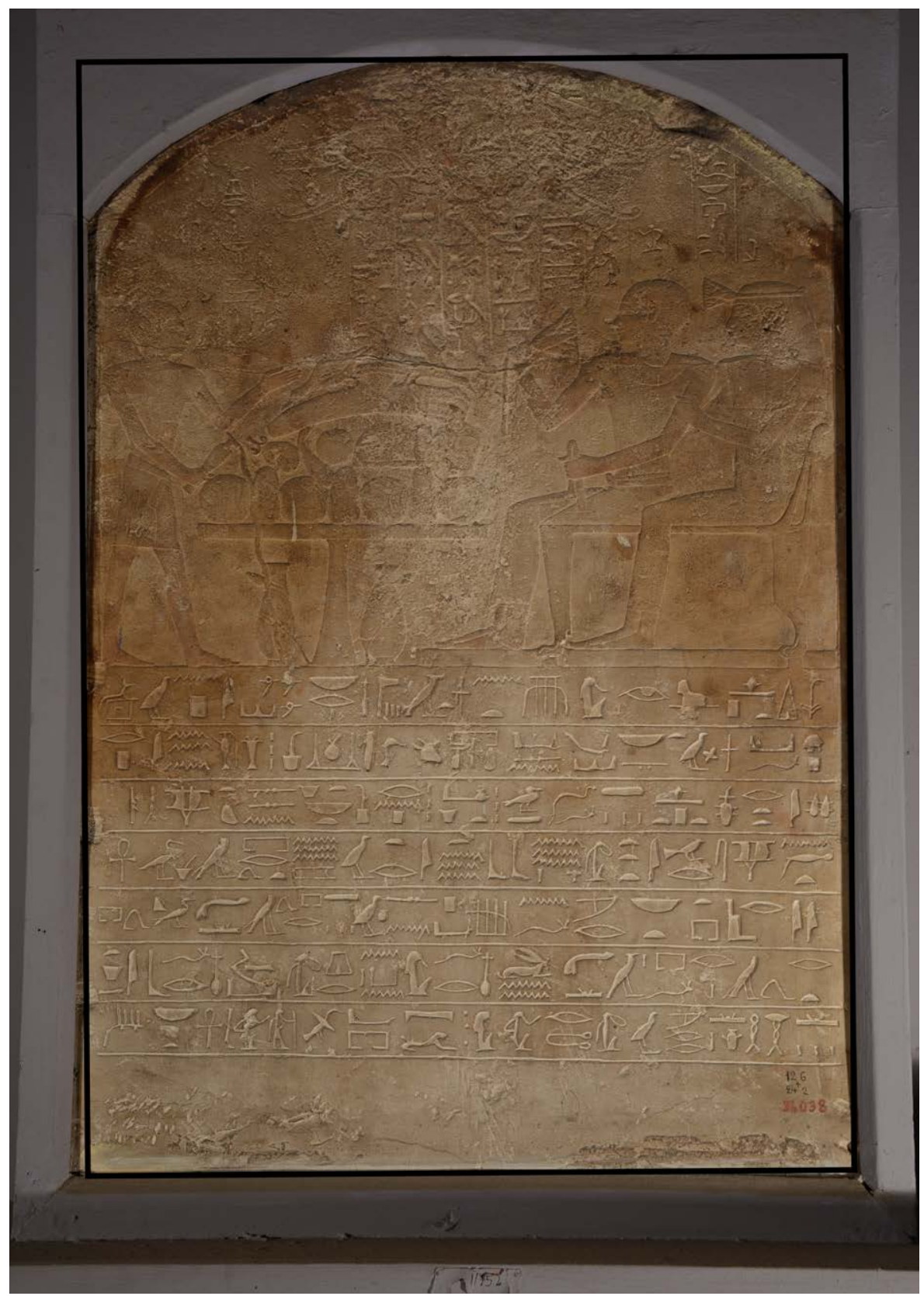

Figura 1. La estela de Paser (CG 34038) ๑Museo Egipcio de El Cairo. Fotografía reproducida con el permiso del Museo Egipcio de El Cairo.

una falda que llega hasta sus tobillos. Sostiene y huele un loto con su mano derecha, mientras que en la izquierda lleva una pieza de lino doblado. La mujer, detrás, lo abraza tomando con su mano izquierda la mitad superior del brazo izquierdo del hombre y con la derecha el otro hombro. Ella porta una peluca con un loto sobre su frente, un collar y un vestido que se sujeta sobre el hombro derecho y llega hasta los tobillos.

Sobre la mesa de ofrendas y el hombre, una inscripción de siete líneas verticales presenta la ofrenda en su formulación característica y a su destinatario, el jefe del almacén ( $h r y \check{s}^{\prime}$ ), Paser. En esta instancia, el signo $p 3$ se encuentra en muy malas condiciones, y es posible confirmar su lectura a partir de la inscripción inferior, más extensa y en mejor estado. Sobre la mujer, los signos la identifican como su esposa y señora de la casa $(\underset{\square}{\circ}$ nbt pr), Teti. 
2. Los signos que corresponden a los sonidos t y p están invertidos. Lacau (1909, p. 72) ya lo había notado en su transcripción de la estela.

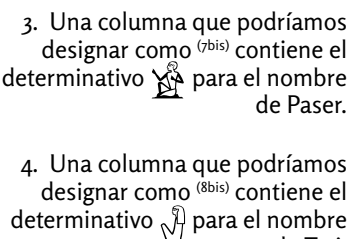

4. Una columna que podríamos designar como ${ }^{\text {(8bis) }}$ contiene el determinativo $\$$ para el nombre de Teti.

5. La palabra debiera escribirse con el determinativo -que aparece efectivamente luego del determinativo 50 -, y no con con ○. Lacau (1909) To notó y señaló en su transcripción.

6. La preposición debiera escribirse con y no con . Lacau (1909) lo noto y señaló en su transcripción.

\section{Transliteración y traducción}

Para la presentación de esta transliteración y traducción hemos respetado la disposición original de la inscripción en la estela. Los errores originales han sido allí corregidos, de acuerdo con las observaciones que realizó Lacau (1909) en su edición, que a continuación apuntaremos. En la Figura 2 se ofrece un esquema que incluye la transcripción.

Sección 1. Columnas sobre la escena de presentación de ofrendas, de izquierda a derecha:

(1) $h r(y)-h b t$ ? $3 n y$

(2) $h t p^{2}$ di nsw h3 $t$

(3) h’ hnkt

(4) h3 k3w h3 $3 p d w$

h3 sntr mrht

${ }^{(5)}$ ht nbt nfr w3b n k3

${ }^{\left({ }^{6}\right)} n$ hry $\breve{s n}^{{ }^{(7)}} p 3 s r^{\text {(7bis) } 3}$

${ }^{(8)} h m t$.f nbt pr tti ${ }^{(8 \mathrm{bis}) 4}$

Sección 2. Líneas horizontales:

(1)htp di nsw wsir hnty imntw

$n \underline{t}$ ฯ 3 nb r st 3 w inpw

${ }^{(2)} t p d w$. fimy $w t$

$n b t 3-d s r$

di.sn prt-hrw

k3 3pdw t šsw sntrw

mrht kbhw irp ${ }^{(3)}$ irtt

$h t p \underline{d} f 3 d r p$

rnpi nbt ssn $n \underline{d} m^{(4)} n$ mhyt

swri ${ }^{5} \mathrm{mw}$ hr bbt itrw

prt $m b 3{ }^{C} n h^{(5)} y$

$r$ st nbt $m r n . f$

šsp snw pr m-b3h

${ }^{\top} k$ pr $m r p^{(6)} r . f$

$m-b 3 h^{6} w n n-n f r$

$n k 3 n$ grw

$m 3^{r} n f r b i t^{(7)} w 3 h-i b$

mry rmt hry $\breve{s} n^{\complement} p 3 s r$

whm `nh nbt im3h
(1) El sacerdote lector Aany.

(2) Ofrenda que da el rey: un millar de panes,

${ }^{(3)}$ un millar de cervezas,

${ }^{4}$ un millar de bueyes, un millar de aves, un millar de incienso y aceite;

${ }^{(5)}$ todas cosas bellas y puras para el $k a$

${ }^{(6)}$ del jefe del almacén ${ }^{(7)} \mathrm{Paser}^{\left({ }^{(7 b i s)} \text {. }\right.}$

${ }^{(8)} \mathrm{Su}$ esposa, la señora de la casa Teti ${ }^{(8 b i s)}$.
(1) Ofrenda que da el rey a Osiris Khentyimentu,

gran dios, señor de la necrópolis; a Anubis ${ }^{(2)}$ sobre su montaña, el que está en el $w t$, señor de la tierra sagrada.

Que ellos den una ofrenda invocada: bueyes, aves, pan, linos, inciensos, aceite de libación, vino, ${ }^{(3)}$ leche, ofrendas y comida presentadas, todas las hierbas para respirar el dulce viento ${ }^{(4)}$ del norte,

beber agua sobre la corriente del río. Salida como ba viviente ${ }^{(5)}$ hacia todo lugar amado por él.

Recepción de ofrendas para ser ofrecidas, y entrar y salir de su casa ${ }^{(6)}$ en presencia de Unenefer. Para el $k a$ del silencioso, de carácter justo y bueno( ${ }^{(7)}$, paciente. Amado (por la) gente, el jefe del almacén Paser, repitiendo cada vida en veneración.

\section{Comentarios sobre el texto}

La mitad superior del monumento - que denominamos Sección 1- consiste en una combinación entre imagen y texto asociada a la presentación de ofrendas. Las inscripciones, por un lado, identifican a los personajes de la escena y, por otro, enuncian una clásica fórmula de ofrendas. 


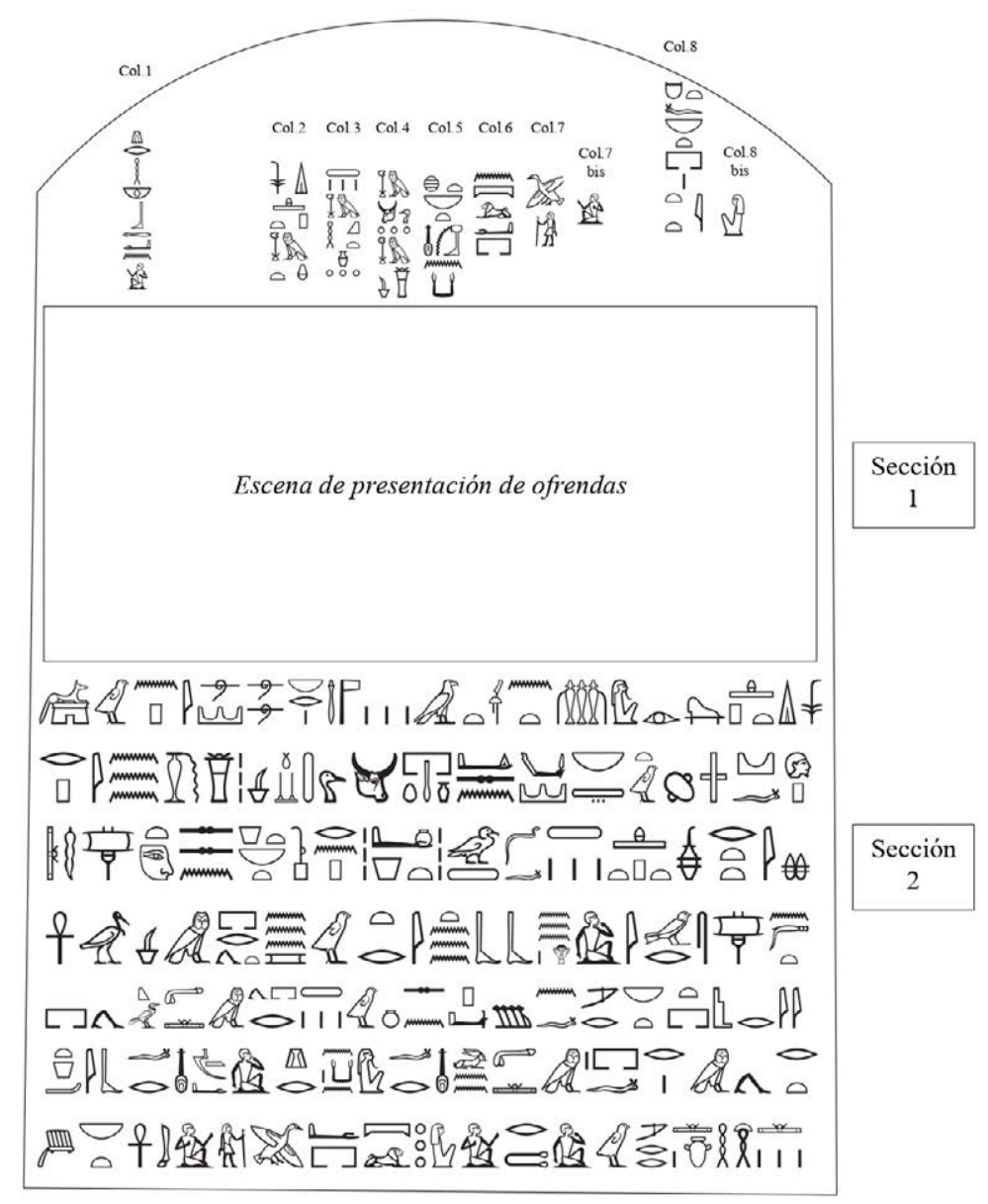

Figura 2. Esquema de la estela de Paser (CG 34038).

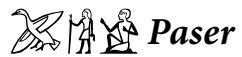

El propietario y destinatario de la estela es un individuo llamado Paser, identificado como un miembro de la administración egipcia a partir de la ostentación del título de

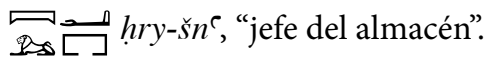

Este rótulo es relevado por Jeanette Anne Taylor (2001) en su índice de títulos de la dinastía XVIII. Es correspondido con una aparición en CG 34050, mas no es indicado el registro en CG 34038. Posteriormente, es incluido por Abdul Rahman Al-Ayedi (2006) en un índice de títulos del Reino Nuevo, que incluye jurisdicciones administrativas, militares y religiosas. Allí se puede apreciar una profusión mayor de la denominación $h r y-\check{s} n^{\complement}$ presente en sellos, papiros, tumbas, dinteles y estelas, que incluye la notación de Paser. Esta evidencia relevada por Al-Ayedi proviene de Saqara, Hermópolis, Malkata y Tebas. Sin embargo, cabe destacar que en estos casos el título hrry-šn` no implica una determinación de mayor especificidad en cuanto al sitio de trabajo. Es decir, no es precisa y/o explícita la localización o jurisdicción del šn ${ }^{r}$. Al-Ayedi (2006) desglosa luego en su índice una cantidad de ámbitos posibles de desempeño de esta función: de Amón, del templo de Amón y del w`bt "taller" (Wb. I, p. 284).

El šn', aquí traducido como almacén, combina los significados de lugar de almacenamiento y establecimiento de trabajo (Wb. IV; Faulkner, 1991 [1962]). Se 
trata de un centro de producción que aglutina una serie de actividades económicas. Está atestiguado para el culto de los dioses Amón, Osiris, Khonsu y Werthekau (Mekawy Ouda, 2014), por lo que se asocia estrechamente a la institución del templo. Debido al predominio del culto a Amón en Tebas y a una mayor supervivencia de su documentación (Haring, 2013) es el $s n^{\complement}$ del templo de Karnak el que está mayormente atestiguado y a partir del cual se pueden estudiar funciones asignadas y responsabilidades adquiridas. De acuerdo con esta información disponible, el lugar del $\breve{s} n^{`}$ en la organización del templo es bien especial (Eichler, 2000): allí se procesan la materia prima de productos agrícolas, la comida, las ofrendas diarias y las especiales. También se producen ropa y linos. En términos más amplios es caracterizado, durante el Reino Nuevo, como un "centro de redistribución" crucial en el sistema económico (Polz, 1990, p. 47). Es posible identificar un vínculo entre el $p r \varsigma^{\varsigma} n^{`}$ y la organización económica egipcia ya desde finales del Reino Antiguo, de acuerdo con Papazian (2005).

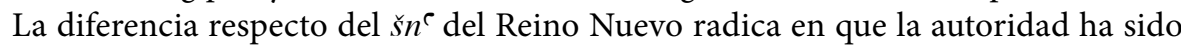
transferida al templo, reemplazando el control directo que mantenía el palacio durante el Reino Antiguo.

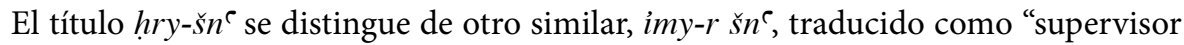
del almacén". En el estudio que Daniel Polz dedica a la institución y su organización durante el Reino Nuevo, se expone una diferencia de estatus y función: mientras que el imy-r $r n^{`}$ se convierte gradualmente en un título con estatus administrativo, el hrry $\check{s} n^{\complement}$ se vuelve un título de gerencia intermedia, lo que implicaría un trabajo real dentro del $\breve{s} n^{\complement}($ Polz, 1990).

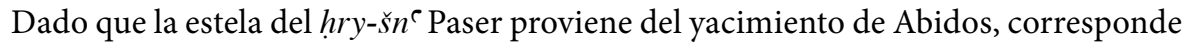
indagar por la existencia de la institución $\breve{s}^{\ulcorner}$en el sitio, como parte del interrogante por la jurisdicción no explicitada para la que actuaba Paser como jefe. La respuesta no se revela sencilla o directa y caben al menos un par de posibilidades. Existe registro de un $\breve{s} n^{\complement}$ hacia el este del templo principal de Sesostris III, construido durante el Reino Medio: el $\check{s} n^{\ulcorner} \cdot w-(z-n-w s r . t)$ (de acuerdo con Cahail, 2014; véase también Smith, 2010). Las excavaciones y estudios aquí realizados muestran que el horneado de pan y la fabricación de cerveza se constituyen como actividades principales, aunque también se atestiguan otras actividades económicas como procesamiento de carne, pescado y vino, trabajo en metal, producción de lino y cerámica (Smith, 2010). Así, el área se identifica como un $\breve{s} n^{\ulcorner}$por evidencia arqueológica, pero también por materiales textuales como impresiones de sello e inscripciones en escarabajos (Smith, 2010).

Por su parte, durante el Reino Nuevo se presenta cada vez mayor evidencia de actividad cultual y, por ende, económico y administrativa. Las excavaciones en la llamada "zona votiva" llevadas adelante por Mary Ann Pouls-Wegner (2012) revelan de forma continua nuevos descubrimientos que complejizan nuestra interpretación del sitio para el período. Existe evidencia de capillas de la dinastía XVIII dedicadas a Amenofis I y Ahmose, Tutmosis III y Amenofis III (O'Connor, 2009). Las excavaciones y el descubrimiento de la estructura de Tutmosis III —en coincidencia con la datación de Paser- entre el llamado enclosure del templo de Osiris y el cementerio norte, fueron realizadas por Pouls-Wegner en el año 1996. La construcción está posicionada de modo que demarca el ingreso a la ruta procesional que lleva a Umm el-Qaab y se inserta así en el programa constructivo del paisaje para el desarrollo del festival de Osiris. Pouls-Wegner (2011) ha analizado la cerámica encontrada en el sitio y la asocia tanto con la actividad ritual general como con la provisión estatal de las estructuras de culto de Tutmosis III. Esta estructura parece ser compleja y en alto funcionamiento, motivo por el cual es posible que el $\breve{s} n^{c}$ del que se hace cargo Paser, aun cuando no haya sido identificado como tal, esté asociado a esta sede ritual. 
No obstante, cabe también la posibilidad de que Paser no hubiera actuado en Abidos, sino en otro espacio del territorio egipcio. Su estela emplazada en el yacimiento sólo respondería entonces a una actividad ritual y no se vincularía necesariamente con una inserción dentro de un círculo de elites local. La escueta evidencia textual, en este punto, inhibe la confirmación de alguna de estas hipótesis.

\section{คำ Teti}

La figura femenina sentada al lado de Paser es presentada como $\square$ \bt pr "señora de la casa”, Teti. El título que porta es el más común entre las mujeres egipcias, por lo menos a partir de la dinastía XII (Robins, 1993). En principio podría designar un estatus de mujer casada - aunque no necesariamente - y remite a un rol de administración del dominio doméstico (Robins, 1993).

Teti lleva su pelo ataviado con una peluca tripartita, junto con un tocado con una flor de loto. Es relevante señalar esta caracterización, dado que puede considerarse al cabello como un atributo que permite observar e identificar información sobre género, edad y estatus (Robins, 1999). Efectivamente, la representación con el estilo tripartito - con el cabello dividido en tres partes, dos cayendo a cada lado de la cara y la otra hacia atrás - la posiciona en el grupo de madres, esposas e hijas (casadas) que se figura con estas características durante la primera parte de la dinastía XVIII (Robins, 1999).

Cabe subrayar aquí la particularidad de su tocado. Se trata de un adorno que luce una flor de loto azul, muy extendida en el arte egipcio como parte de bouquets, ofrendas, objetos decorativos y estructuras arquitectónicas (Ossian, 1999). Su significación simbólica la vincula con el dios solar Ra y su venida a la existencia a partir de una flor de loto sobre las aguas primigenias. En este sentido se torna relevante en un contexto funerario conjugándose con la aspiración de revitalización del difunto, que espera renacer desde un loto como Ra (Manniche, 2011 [1989]) y se incluye como parte del repertorio iconográfico en estelas funerarias y en escenas de tumbas. Muy a menudo, el difunto y otras personas representadas en escenas funerarias llevan una flor de loto en sus manos ${ }^{7}$. Paser mismo, en la estela CG 34038, la ostenta frente a la mesa de ofrendas. Asimismo, puede formar parte de tocados como el que porta $\mathrm{Teti}^{8}$. El aroma dulce de la flor es reconocido como un atributo específico de la especie, lo que la vuelve propicia para un contexto ritual. Este perfume también es asociado al renacimiento, por lo que olerlo se vuelve simbólico y otorga vida a quien lo hace.

Teti, sentada detrás de su esposo y abrazándolo, no es incorporada discursivamente como destinataria de la ofrenda. Sin embargo, su inclusión en imagen y nombre habilitan su participación en el ritual y probablemente recibiera algún beneficio material y simbólico respecto del contexto oferente.

\section{Eany}

El personaje representado sobre la izquierda vierte agua sobre la mesa de ofrendas y

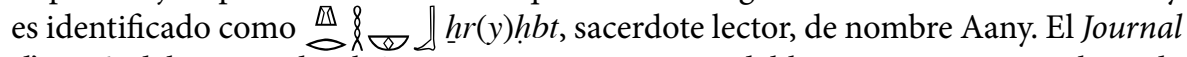
d'Entrée del Museo de El Cairo apunta que se trata del hijo - suponemos, claro, de Paser y Teti-. No es posible confirmar esta filiación a partir del estado actual de la estela, aunque existe cierto grado de probabilidad respecto de esta información dado que es usual la representación del hijo ofrendando a sus padres o encabezando el ritual de ofrendas.

Aany, como sacerdote lector, se inserta en una estructura religioso-administrativa en la que aun cuando pudiera ser prevalente la cualidad de variación en la organización sacerdotal (Spencer, 2010), es posible identificar tipos y roles de oficiantes. Así, el
7. En la tumba de Rekhmira, por caso, en el muro norte del pasaje la escena muestra a la pareja sentada frente a la mesa de ofrendas, y la esposa lleva en sus manos una flor de loto (Davies, 1943, pl. CIII).

8. En TT 38, la esposa lleva un tocado como el observado en CG 34038 en una escena de libación de ofrenda (Davies, 1963, pl. I). En la tumba de Paheri en el-Kab, el difunto y su esposa se encuentran sentados frente a la mesa de ofrendas, en una posición similar a la que observamos en CG 34038: la mujer lleva como tocado un adorno con la flor de loto (Tylor y Griffith, 1894, pl. IX). Es posible a veces que en lugar de un loto, el tocado esté ataviado con un cono aromático de aceites o ungüentos. 
sacerdote lector es identificado como una posición común entre los sectores de elite, que puede ser a menudo combinada con otro tipo de títulos administrativos, palaciegos, o del mismo templo (Spencer, 2010). Su principal habilidad, tal como el nombre lo indica, es la de leer y en este sentido su función preeminente consistía en recitar textos religiosos tanto en el ámbito del templo como en rituales funerarios (Teeter, 2017 [2011]). En este último contexto resulta fundamental su participación, por caso, en la vocalización de "conjuros" que acompañan al difunto en su transición hacia la calidad de $a k h$ (Teeter, 2017 [2011], p. 22), incluyendo el momento ritual de apertura de la boca (Spencer, 2010). El uso de la voz como acto performativo vuelve a los textos activos y efectivos, de modo que a través de la recitación adquieren realidad y materialidad (Contardi, 2010). El rol del sacerdote lector, en este sentido, es de vital importancia.

El acto puntual que Aany efectúa en la estela funeraria de Paser es el de la purificación de las ofrendas. Con una jarra vierte agua sobre la mesa repleta de productos comestibles. La jarra que se usa $(\bar{\delta})$ es la que, con agua saliendo de ella ( $\{$ [) , funciona como determinativo de la palabra kbḥ "libación". El hecho de verter agua y, probablemente, recitar un "conjuro" activaba los elementos representados sobre la mesa, de forma que se les dotaba de un poder dador de vida. Tal acto le daba vida al difunto, fortaleciéndolo e incluyéndolo igualmente en el aprovisionamiento a los dioses en el espacio del Más Allá (Assmann, 2005 [2001]). Puede existir a su vez una conexión entre el agua de libación y el agua que se expande con la llegada de Hapy, la inundación (Assmann, 2005 [2001]). El sentido de fertilidad y abundancia implicado en este fenómeno se traduce igualmente en el acto de la purificación.

\section{La fórmula y la mesa de ofrendas}

El texto central de esta inscripción superior consiste en una fórmula de ofrendas, un conjunto de palabras combinadas de forma relativamente fija que se estandariza en torno al Reino Medio (Barta, 1968, 1982). Mark Collier y Bill Manley (2007 [1998]) nos informan sobre las funciones de este tipo de inscripciones. Por un lado, se distingue un ámbito oficial en el que la posición del difunto como "justificado" se vincula con su actuación en la vida terrenal. El éxito en este sentido, asociado a su actuación en torno al rey, sería materializado en la noción de "reversión de ofrendas" (Leprohon, 2001, pp. 569-570) por medio de la cual se permite al difunto participar de las ofrendas a las divinidades en los templos en nombre del rey. Por otro lado, la función personal se asocia con el ámbito privado y familiar del difunto, que ofrece y perpetúa estas ofrendas. El lugar central del rey en la fórmula, en cualquier caso, implica una "sanción oficial" para el objeto o las acciones que se referirán (Allen, 2006, pp. 14-15), y confirma su rol cósmico como "fuente de todos los bienes" (Leprohon, 2001, p. 570).

La primera parte de la fórmula de CG 34038, $¥ \Delta \frac{\theta}{a} h t p$ di $n s w$, la "ofrenda que da el rey", introduce en este caso el inventario de provisiones. El término a htp, además de su traducción como ofrenda, refiere también a la "satisfacción" o "alegría", lo que puede remitir a los sentimientos del difunto ante la presentación de los bienes (Leprohon, 2001). Esta enumeración incluye pan y cerveza (vocablos escritos en forma extendida), bueyes, aves, incienso y aceite (vocablos escritos de forma abreviada). Se dice que estos bienes son "todas cosas buenas y puras" en una formulación general que implica la realización previa de un ritual de purificación. El destinatario de la ofrenda es presentado como el " $k a$ del jefe del almacén Paser". El \& $k a$, como fuerza vital, es lo que distingue a un ser humano vivo de uno muerto. La muerte ocurriría cuando el $k a$ deja el cuerpo (Allen, 2014 [2000]). Por ello, este $k a$ debe ser alimentado con comida y bebida, lo que lo hace objeto de las ofrendas de provisiones. A su vez, el $k a$ se asocia a la dimensión social del individuo. En este sentido, es la forma en la cual el difunto puede estar presente en la tumba y ser receptor de las acciones de culto. Las ofrendas dirigidas hacia él son el modo en que se permite que el difunto continúe formando parte de la comunidad (Assmann, 2005 [2001]). 
Esta breve inscripción de ofrenda se complementa con la imagen de la mesa, que adiciona otros productos. Sobre la misma, es posible distinguir cebollas, un melón, uvas, un ave y distintos tipos de panes. Las cebollas - en ramos- constituyen un ítem regular en la representación de mesa de ofrendas. Formaban parte de la dieta base junto con el pan y la cerveza (Manniche, 2011 [1989]). Robins (2016) establece una conexión entre la escritura que la designa $-\underline{h} \underline{d} w-$ y la raíz $h \underline{h}$, traducible como "blanco, brillante", asociándola entonces con una noción de luminosidad en la manifestación de los dioses y en la misma transfiguración del difunto como akh. Asimismo, el melón ( $s \breve{p} t)$ que se incluye en la mesa de Paser también le resulta a la autora similar a la palabra $s \breve{p} p$ "luz, brillante, blanco" (Robins, 2016, p. 122). Las uvas se vinculan con Osiris y la resurrección, la inundación y la fertilidad. Desde el proceso de crecimiento hasta la producción, ellas manifiestan una capacidad regenerativa que las asocian a aquellas cualidades (Robins, 2016). Por su parte, el ave y los panes constituyen ítems básicos de la dieta antiguo-egipcia y su presentación es aquí reforzada en imagen y texto.

Ciertamente, existe una complementariedad entre texto e imagen que tiene como consecuencia la efectivización del ritual presentado. De acuerdo con Jan Assmann (1992), el culto en el antiguo Egipto está basado en una división tripartita entre acción, representación icónica y recitación. En el caso de los equipamientos funerarios, existe una evolución en la que se pasa de depositar provisiones reales de comida y bienes a su reemplazo por modelos realizados en piedra, por ejemplo, hasta el punto último en que tales provisiones son sólo enumeradas en una lista como una inscripción. El culto funerario, así, consistirá finalmente en la recitación de esa lista de ítems. Este inventario se convierte en un texto de tipo sagrado y su vocalización lo vuelve profundamente eficiente, con lo que adquiere un poder representativo simbólico y divino altamente efectivo (Assmann, 1992). Esta es precisamente la función de la representación de la mesa de ofrendas y la enumeración de las provisiones otorgadas: se transforman en símbolos de conmemoración y continuidad del ritual de ofrendas. Esta fijación, a su vez, permite que, si la ofrenda de comida efectivamente se detuviera, la escritura y su recitación garantizarán mágicamente un aprovisionamiento eterno (Leprohon, 2011).

La mitad inferior del monumento - que denominamos Sección 2-contiene una inscripción que se extiende por siete líneas en perfectas condiciones de conservación y presenta una nueva fórmula de ofrendas con otros aditivos.

\section{La fórmula de ofrenda y la transfiguración del difunto}

La reiterada fórmula htp di $n s w$ dedica ahora la ofrenda que da el rey a Osiris y Anubis como primeros destinatarios. De acuerdo con Franke (2003) la función de estos dioses no sería en realidad la de la recepción de la ofrenda, sino la de oficiar como su garantía. El rey continúa siendo el donante primario, pero la ofrenda es dada ahora a los dioses que, a su vez, la otorgarán al difunto (Leprohon, 2001).

Osiris es denominado con sus epítetos usuales: "Khentyimentu" (asociado a su posición como el primero de los occidentales, es decir, de los difuntos), "gran dios" - como epíteto frecuente para distinguir la calidad divina- $\mathrm{y}$ "señor de la necrópolis", nuevamente en relación con su ámbito funerario de pertenencia. Anubis, por su parte, es presentado junto con los calificativos "sobre su montaña", que indica su posición líder sobre el desierto occidental y "el que está en el $w t$ ", expresión que puede traducirse también como "el que está en el lugar de embalsamamiento" o "el que está en las envolturas de momia". Esto se vincula con el hecho de que el término $w t$ remite a las vendas que se usan en el cuerpo con posterioridad al proceso de la momificación y resulta pertinente entonces describir al dios Anubis - que encabeza el proceso- con expresiones vinculadas al vendaje (DuQuesne, 2012). Por último, se lo invoca como "señor de la tierra sagrada", otra forma de denominar la preeminencia sobre el mundo de los muertos. 
Esta ofrenda que da el rey a los dioses será a su vez dada como prt hrww, una ofrenda invocada - u ofrenda de invocación-. Esta expresión podría traducirse como "lo que sale a la voz" y remite al principio de que pronunciando los nombres de las ofrendas junto con el nombre del difunto, éstas vienen a la existencia, se tornan reales (Teeter, 2017 [2011]). Al mismo tiempo, se combina con la idea de que al escuchar la voz del sacerdote recitando la ofrenda, el $b a$ del difunto "saldría" del Otro Mundo y recibiría la ofrenda en cuestión (Assmann, 2005, p. 330). En este caso, la ofrenda consiste en una enumeración más extensa de bienes, que incluyen los clásicos pan y cerveza (incorporados asimismo a la escritura de $\mathrm{L}_{0} \vec{\sigma}$ prt $h r w$ ), carne y aves, lino e incienso (vocablos escritos de forma abreviada), aceite de libación, vino y leche (vocablos escritos de forma completa). Estos ítems se adicionan a los términos genéricos htpw "ofrendas", $\underline{d} f$; "provisiones" y rnpi "hierbas".

Las siguientes acciones enunciadas implican otra dimensión corpórea fundamental para el devenir en el mundo funerario: respirar el dulce viento del norte y beber agua sobre la corriente del río. Para Assmann (2005 [2001]), existe un momento de vulnerabilidad corporal al transitar la muerte que es expresado de modo contundente en la enumeración de partes del cuerpo y acciones vinculadas a ellas. Al colapsar la unidad de la persona, según el autor, ésta tiene que ser restaurada al difunto. Las acciones presentadas en esta inscripción, entonces, pueden vincularse con este particular trance como una forma de enfrentarlo y superarlo: se trata de acciones nutricias que habilitan la reconstitución de Paser como difunto.

El resultado de la ofrenda de invocación se materializa en la "salida como ba viviente hacia todo lugar amado por él". En este tramo de la inscripción, el difunto Paser ha alcanzado una de las transformaciones a las que se aspira durante la transfiguración que implica el pasaje al Más Allá (Assmann, 2005 [2001]). La emergencia como ba viviente implica la posibilidad de circular libremente hacia afuera y nuevamente hacia adentro de su casa, es decir, la tumba. Este deambular constante se articula con el devenir del día y de la noche y desdibuja las fronteras con el Más Allá. La libertad de movimiento es un rasgo intrínseco del ba como elemento (Assmann, 2005 [2001]) y como tal se perpetúa en la eternidad. La recepción de ofrendas se reitera y se alude a la presencia de Unenefer, otra forma de Osiris que puede ser traducida como "el que continúa siendo perfecto" (Collier y Manley, 2007 [1998], p. 69).

La dedicatoria indica finalmente, de nuevo, como destinatario el $k a$ de Paser. Son llamativas en este punto la notación no sólo de su título en la estructura oficial egipcia, sino también la valoración de cualidades personales: silencioso, de carácter justo y bueno, paciente. Se trata de virtudes bien ponderadas entre los textos conocidos como "enseñanzas". En la llamada Enseñanza de un hombre a su hijo, por ejemplo, se alienta a exhibir "un (buen) carácter, (ser) un hombre silencioso, justo, bien dispuesto" (Simpson, 2003 [1973], p. 176). Por su parte, en relación a la paciencia, en la Instrucción de Amunnakhte se aconseja "haz tu corazón paciente en su odio" (Simpson, 2003 [1973], p. 222), mientras que Ptahotep reza "si eres un hombre de autoridad, sé paciente cuando estás escuchando las palabras de un peticionante” (Simpson, 2003 [1973], p. 137).

9. La autora registra otra ocurrencia del epíteto en TT 53 (Urk. IV, 1218.3). Se trata de la tumba de Amenemhat, quien desarrolló actividades en el templo de Amón durante el reinado de Tutmosis III. Se trataría así de un coetáneo a Paser.
Estos calificativos aplicados a Paser son acompañados igualmente por la expresión "amado (por la) gente", un epíteto que Taylor (2001) registra entre los no-reales propios de la dinastía XVIII". El registro formular se aparta en este punto de la dimensión nutricia y ritual propia de la presentación de ofrendas para justificar en el carácter de Paser la pertinencia del desarrollo y mantenimiento de ese culto funerario. En este sentido, es sugerente pensar que aún cuando el monumento no registra una instancia de justificación per se - como sí tal vez podría registrarse en la tumba misma del funcionario-, la inscripción en esta estela recupera una enunciación de valores que abona a la transformación y consideraciónde Paser en un justo de voz, venerado. 
Precisamente, la frase que culmina la inscripción apela a la continuación de la vida en ese estado de veneración.

\section{A modo de cierre. La estela de Paser en contexto}

La estela CG 34038, perteneciente al jefe del almacén Paser forma parte del repertorio funerario que compone el paisaje abideano. Encontrada en el cementerio norte, probablemente haya sido emplazada en el sitio como parte de una fuerte tradición: el culto al dios Osiris y la participación en las festividades en su nombre. Los llamados misterios de Osiris eran el núcleo del ciclo ritual que se desarrollaba en los complejos de templos de Abidos, ya desde el Reino Medio (Griffiths, 1975; Lavier, 1998).

Los trabajos de investigación realizados por la Universidad de Pensilvania y de Yale, por la Expedición a Abidos del Instituto de Bellas Artes de la Universidad de Nueva York y por la Universidad de Toronto en la llamada "zona votiva", vienen revelando que el sitio conformaba un lugar apropiado para la actividad real y no real en torno al culto de Osiris. En la estela de Paser no se detectan referencias puntuales o explícitas de participación en los rituales específicos. Sin embargo, el contenido - en tanto programa decorativo y presentación de fórmula de ofrendas - y la proveniencia de la estela remite a la inserción del monumento en este circuito ritual.

Por otra parte, la estela ofrece información acotada sobre la estructura administrativa del estado egipcio activa en Abidos durante el reinado de Tutmosis III. Paser oficia como hry šn ${ }^{\complement}$ y se convierte así en indicio para continuar indagando en la existencia de tal institución en el sitio, su funcionamiento y relación con establecimientos similares. La articulación con la evidencia arqueológica, en actualización constante, sería vital en este punto. Es posible igualmente que no existiera correspondencia entre las tareas oficiales de Paser y el sitio de Abidos y que la conexión se estableciera exclusivamente en función de la participación en la actividad ritual.

El enlace entre la dimensión de actividad ritual y de actividad administrativa que se expresa en este tipo de monumentos podría permitir vislumbrar, a su vez, una actividad intensa en el sitio, que invitaría a repensar la noción del predominio de Tebas y el culto a Amón durante la dinastía XVIII.

\section{Agradecimientos}

Agradezco al Museo Egipcio de El Cairo por el permiso para publicar esta estela, a su directora Dra. Sabah Abdel Razek y a Marwa Abd el-Razek Mahmoud (Registration, Collections Management and Documentation Department) por su atención y colaboración durante mi visita al Museo en el mes de enero de 2019. Este estudio se enmarca en el Proyecto de Investigación y Desarrollo "Estudios sobre las elites en Abidos a partir de las estelas del Museo de El Cairo", radicado en la Universidad Nacional de La Plata y dirigido por la Dra. Andrea Zingarelli. Agradezco también a ella y al Dr. Pablo Martín Rosell por sus comentarios sobre este manuscrito, así como a los evaluadores que ofrecieron valiosos aportes durante el proceso de edición. 


\section{Q Referencias citadas}

"Al-Ayedi, A. R. (2006). Index of Egyptian Administrative, Religious and Military Titles of the New Kingdom. Ismailia: Obelisk Publications.

"Allen, J. P. (2006). Some aspects of the non-royal afterlife in the Old Kingdom. En M. Barta (Ed.), The Old Kingdom Art and Archaeology. Proceedings of the Conference held in Prague, May 31-June 4, 2004 (pp. 9-17). Praga: Charles University.

"Allen, J. P. (2014 [2000]). Middle Egyptian. An Introduction to the Language and Culture of Hieroglyphs. Nueva York: Cambridge University Press.

»Assmann, J. (1992). Semiosis and Interpretation in Ancient Egyptian Ritual. En S. Biderman y B. A. Scharfstein (Eds.), Interpretation in Religion (pp. 87-109). Leiden \& Nueva York: E. J. Brill.

»Assmann, J. (2005 [2001]). Death and Salvation in Ancient Egypt. Ithaca-Londres: Cornell University Press.

" Barta, M. (1968). Aufbau und Bedeutung der altägyptischen Opferformel. Glückstadt: J. J. Augustin.

» Barta, M. (1982). Opferformel. En W. Helcky E. Otto (Eds.), Lexicon der Ägyptologie. Band IV (cols. 585-586). Wiesbaden: Otto Harrassowitz.

"Cahail, K. M. (2014). In the shadow of Osiris: non-royal Mortuary Landscapes at South Abydos during the Late Middle, and New Kingdoms. (Tesis Doctoral inédita) University of Pennsylvania, Estados Unidos.

»Collier, M. y Manley, B. (2007 [1998]). Introducción a los Jeroglíficos Egipcios. Madrid: Alianza Editorial.

»Contardi, F. (2010). Egyptian Terms Used to Indicate the Act of Reading: An Investigation about the Act of Reading in Egyptian Society. En F. M. Fales y G. F. Grassi (Eds.), Camsemud 2007. Proceedings of the 13th Italian Meeting of Afro-Asiatic Linguistics (pp. 261269). Padua: S.A.R.G.O.N. Editrice e Librería.

»Davies, N. de G. (1943). The tomb of Rekh-mi-Rē at Thebes: Volume II. Nueva York: Metropolitan Museum of Art.

"Davies, N. de G. (1963). Scenes from Some Theban Tombs (Nos. 38, 66, 162, with excerpts from 81). Oxford: Griffith Institute.

»DuQuesne, T. (2012). Jmjwt. En W. Wendrich (Ed.), UCLA Encyclopedia of Egyptology, Los Ángeles, http://digital2.library.ucla.edu/viewltem.do?ark=21198/zzoo2bp8x1 (Acceso: 17 de abril, 2019)

"Eichler, S. S. (2000). Die Verwaltung des "Hauses des Amun" in der 18. Dynastie. Hamburgo: Helmut Buske Verlag.

»Erman, A. y Grapow, H. (1926-1961). Wörterbuch der Aegyptischen Sprache. 5 volúmenes. Berlín: Akademie Verlag.

» Faulkner, R. O. (1991 [1962]). A Concise Dictionary of Middle Egyptian. Oxford: Griffith Institute \& Ashmolean Museum.

» Franke, D. (2003). The Middle Kingdom Offering Formulas - a Challenge. Journal of Egyptian Archaeology, 89, 39-57. 
》 Griffiths, J. G. (1975). Hakerfest. En W. Helck y E. Otto (Eds.), Lexicon der Ägyptologie. Band II (cols 929-31). Wiesbaden: Otto Harrassowitz.

»Haring, B. (2013). The Rising Power of the House of Amun in the New Kingdom. En J. C. Moreno García (Ed.), Ancient Egyptian Administration (pp. 607-637). Leiden-Boston: E. J. Brill.

"Lacau, P. (1909). Catalogue Général des Antiquités Égyptiennes du Musée du Caire. Nos 34001-34064. El Cairo: Imprimerie de l'Institut Français d'Archéologie Orientale.

" Lavier, M. C. (1998). Les fetes d'Osiris a Abydos au Moyen Empire et Nouvel Empire. Égypte, Afrique et Orient, 10, 27-33.

" Leprohon, R. J. (2001). Offerings: Offerings Formulas and Lists. En D. Redford (Ed.), The Oxford Encyclopedia of Ancient Egypt (Volumen 2, pp. 569-572). Nueva York: Oxford University Press.

" Manniche, L. (2011 [1989]). An Ancient Egyptian Herbal. El Cairo: The American University in Cairo Press.

" Mariette, A. (1880). Catalogue Général des Monuments d'Abydos. París: Imprimerie Nationale.

" Mekawy Ouda, A. M. (2014). Did Werethekau 'Great of Magic' have a Cult? A Disjunction between the Scholarly Opinions and Sources. En K. Accetta, R. Fellinger, P. Lourenço Gonçalves y P. van Pelt (Eds.), Current Research in Egyptology 14 (pp. 105-121). Cambridge: Oxbow Books.

" O'Connor, D. (2009). Abydos. Egypt's First Pharaohs and the Cult of Osiris. Londres: Thames \& Hudson.

» Ossian, C. (1999). The most beautiful of flowers. Water lilies and Lotuses in Ancient Egypt. KMT A Modern Journal of Ancient Egypt, 10(1), 49-59.

"Papazian, H. (2005). Domain of Pharaoh: The Structure and Components of the Economy of Old Kingdom Egypt. (Tesis Doctoral inedita), Chicago University, Estados Unidos.

"Polz, D. (1990). Die Sna-Vorsteher des Neuen Reiches. Zeitschrift für Ägyptische Sprache und Altertumskunde, 117, 43-60.

» Pouls-Wegner, M-A. (2011). New Kingdom Ceramics Associated with the Cult Chapel of Thutmose III at Abydos: Preliminary Analysis and Interpretations. Cahiers de la Céramique Égyptienne, 9, 367-414.

"Pouls-Wegner, M-A. (2012). New Fieldwork at Abydos: the Toronto Votive Zone Project. Near Eastern Archaeology, 75(3), 178-184.

》 Robins, G. (1993). Women in Ancient Egypt. Londres: The British Museum Press.

» Robins, G. (1999). Hair and the Construction of Identity in Ancient Egypt, c. 1480-1350 B.C. Journal of the American Research Center in Egypt, 36, 55-69.

"Robins, G. (2016). Meals for the Dead: the image of the deceased seated before a table of offerings. En C. M. Draycott (Ed.), Dining and Death: Interdisciplinary Perspectives on the 'Funerary Banquet' in Ancient Art, Burial and Belief (pp. 111-127). Leuven: Peeters Press.

» Sethe, K. (1903-1957). Urkunden Der 18. Dynastie: Historisch-Biographische Urkunden 8 volúmenes. Leipzig: J. C. Hinrichssche Buchhandlung.

"Simpson, W. K. (1974). The terrace of the great God at Abydos: the offering chapels of dynasties 12 and 13. New Heaven: Peabody Museum of Natural History of Yale University.

"Simpson, W. K. (Ed.). (2003 [1973]). The literature of Ancient Egypt: An Anthology of Stories, Instructions and Poetry. New Heaven: Yale University Press. 
"Smith, V. E. (2010). Modeling the Mechanics of Temple Production in the Middle Kingdom: An Investigation of the Shena of Divine Offerings Adjacent to the Mortuary Temple of Senwosret III at Abydos, Egypt (Tesis Doctoral inédita). University of Pennsylvania, Estados Unidos.

"Spencer, N. (2010). Priests and Temples: Pharaonic. En A. Lloyd (Ed.), A companion to Ancient Egpyt (Volumen I, pp. 255-273). Singapur: Blackwell Publishing.

» Taylor, J. A. (2001). An index of male non-royal Egyptian Titles, Epithets and Phrases of the $18^{\text {th }}$ Dynasty. Londres: Museum Bookshop Publications.

» Teeter, E. (2017 [2011]). Religion and Ritual in Ancient Egypt. Glasgow: Cambridge University Press.

"Tylor, J. J. y Griffith, F. L. (1894). The tomb of Paheri. Londres: The Egypt Exploration Fund. 